\title{
Impact of the Moral Recovery Program for Drug Surrenderees in Cavite
}

\author{
Eunice M. Carpizo ${ }^{1}$ and Ainee Grace S. Sansano ${ }^{2}$ \\ ${ }^{1}$ Adventist University of the Philippines \\ ${ }^{2}$ Sultan Kudarat State University \\ EMCarpizo@aup.edu.ph
}

\begin{abstract}
The main objective of the study is to evaluate the impact of the moral-recovery program done by different religious organizations in cooperation with the Dangerous Drugs Board (DDB) of the Philippines, Philippine National Police, Local Governments Units, and Non-Government Agencies and various business sectors. A total of 131 drug surenderees from Cavite, Philippines were purposively selected to participate in the study. One hundred fourteen $(87 \%)$ respondents are male and $17(13 \%)$ are female. Survey questionnaires and interviews were used to gather the data to find out how the program made an impact to the morality of the surrenderees. Frequency and percentages were used for statistical analysis. Results showed that after attending the 3-month moral recovery program, $111(85 \%)$ of the drug surenderees resolved to stop using drugs, 64 (49\%) committed to attend church regularly, 98 (75\%) have a better relationship with God, and $23(18 \%)$ have a healthier perspective in life and became more responsible members of their own families. The respondents, who were influenced by their friends to use drugs, after attending the 12-session moral recovery program that lasted for three months, changed their lives dramatically from turning to drugs to turning to God in solving their problems. This proved that the program helped the drug surenderees to improve their lives and relationship with God and with other people. Since this program is mandated by the government, it is recommended that further studies on the impact of the moral recovery program in other areas in the Philippines be done.
\end{abstract}

Keywords: War on Drugs; Drug Surrenderees; Moral Recovery Program.

\section{INTRODUCTION}

The War on drugs is one of the Philippine government's priority programs due to the proliferation of illegal drugs. The widespread sale of these illegal drugs has become a public health concern. As a result of the campaign against drugs, thousands surrendered which prompted the government to conduct moral recovery community-based programs nationwide. SIPAG (Simula ng Pag-asa) is a 12-week recovery program launched in cooperation with the Dangerous Drugs Board (DDB), and in partnership with local churches, various business sectors, non-government organizations, the PNP and local government units across the nation. 
It was first conceptualized in October 2016, when DDB tapped Christ's Commission Fellowship to launch a faith-based recovery program to cater to the thousands of drug dependents who surrendered as part of President Duterte's war against drugs. SIPAG aims to address the emotional, physiological, and relational, as well as spiritual issues battling within the drug dependents and their family members SIPAG desires for the drug dependents to know that there is more to life than substance abuse (Dangerous Drugs Board, 2016).

All drug surrrenderers of Silang, Cavite participated in this recovery program that had its kicked off day on April 9, 2017. Out of 1800 drug surrenderers, around 800 enrolled for the recovery program, of which, 371 participants successfully completed the 12 sessions which ended on June 25, 2017. The closing ceremony on July 30, 2017 was a sense of accomplishment to the government, specifically to the PNP Silang and AUP Community Extension Services, that worked hand in hand for the victory of this program.

The main objective of this research is to determine the impact of the moral-recovery program done by different religious organizations in cooperation with the Dangerous Drugs Board (DDB) of the Philippines, Philippine National Police, Local Governments Units, and Nongovernment Agencies and various business sectors. More specifically, the study sought to answer the following questions:

1. What kind of drugs did the respondents use before they attend the SIPAG program? How they used the drugs and how frequent?

2. What are the changes that they experienced in life after attending the 12 sessions of SIPAG program?

The impact study of the Community Extension Services (CES) program determines to contribute to the following people:

The designed recovery program will help them in the emotional, relational, and spiritual aspects of their well-being, as they participate in the 12-week sessions guided by modules provided by the government.

In responding to the nationwide campaign of His Excellency President Rodrigo Roa Duterte, the PNP Silang, Cavite will gain an accomplishment report that they can use as reference in the implementation of its programs, especially on drug related cases.

This program will help the CES implement its thrusts and will evaluate if the programs are appropriate and beneficial to the community. The result of the program will help the CES to attain its goal to become an outcome-oriented department, which works for the cause of the community within its municipality. 
The Adventist University of the Philippines has been implementing programs that are beneficial to the Silang community. The nine existing colleges are facilitated and coordinated by the CES department. The result of this study will further enhance the services being offered by the institution.

\section{LITERATURE REVIEW}

The number of drug users continues to increase yearly in spite of the drug reduction and rehabilitation programs and policies made by the different countries in the world to reduce the incidence of drug use. The use of drugs illegally is considered as a major problem and a threat to human beings in the whole world. Drug addiction is still the top 20 risk factors for health in the world and among the top 10 risk factors in low-income countries. The estimate of drug users in 2012 was 243 million people worldwide. The number increases to 255 million in 2015 and 275 million in 2016. The estimated prevalence of drug use in 2011-2014 was 5.2\% of the world population. The percentage was increased to 5.3\% in 2015 and $5.6 \%$ in 2016. Drug use is much higher among young people than older people. The most commonly used drugs are cannabis (192 million users), oploids (34 million users), amphetamines (34 million users), ecstasy (21 million users, opiates (19 million users), and cocaine (18 million users) (United Nations Office on Drugs and Crimes, 2017 \& 2018).

Persons who initiate substance use and later develop substance use disorders typically transition through a number of stages, including initiation of use, escalation of use, maintenance, and, eventually, addiction (Kandel, 2002). Addiction is a chronic, relapsing disorder characterized by compulsive drug seeking and use despite adverse consequences. It is considered a brain disorder, because it involves functional changes to brain circuits involved in reward, stress, and self-control, and those changes may last a long time after a person has stopped taking drugs (Goldstein \& Volkow, 2011). Drug dependence has two components: physical dependency and psychological dependency. Physical dependency occurs when a drug has been used habitually and the body has become accustomed to its effects. Psychological dependency occurs when a drug has been used habitually and the mind has become emotional reliant to its effects, either to elicit pleasure or relieve pain, and does not feel capable of functioning without it (Journey Pure, 2019).

Anyone can become a drug abuser. Drug abuse information indicates that all ethnicities, ages, social groups, and genders can have drug abuse problems. Drug abuse is not a character flaw but a medical condition that has developed over time. While no one knows why one person becomes a drug abuser while another doesn't, drug abuse does tend to run in families. The National Institute on Drug Abuse (2018) indicates the following risk factors for developing drug abuse problems:

1. Unstable home environment, often due to drug abuse or mental illness of the parent

2. Poor relationship with parents 
3. Inadequate supervision over adolescent's activities

4. Use of drugs by friends / peers

5. Permissive attitude towards their own drug use and the drug use of the adolescent

6. Behavioral problems combined with poor parenting

7. Poor achievement in school

8. Apparent ambivalence or approval of drug use in the school, peer group or community

9. Availability of drugs in the community, peer group or home

In 2017, President Rodrigo Duterte claimed that there were 4 million drug users in the Philippines. This year, 2019, the President is claiming that the number was increased to 7-8 million drug users (Philstar, 2019; Mazo, 2017). Majority of the drug dependents are poly-drug users and the common drug that they used is shabu or methamphetamine hydrochloride (Philippine Drug Enforcement Agency, 2012). The Philippine National Police (PNP) used the Oplan Tokhang Operations to encourage drug suspects to voluntarily surrender and stop their illegal activities. As a result, an estimated of 1.3 to 1.4 million drug users had voluntarily surrendered for rehabilitation (Inquirer, 2019). The PNP has organized community-based recovery program called Life After Tokhang (LIFT). This program was created based on the findings of the Inter-Agency Committee on Anti-illegal Drugs that about $90 \%$ of the drug dependents do not need to undergo a full rehabilitation program, but need to undergo community-based recovery program instead (GMA News Online, 2017).

On September 19, 2016, the Dangerous Drugs Board (DDB) passed Board Regulation No. 4, series of 2016, entitled "OPLAN SAGIP" mandating the Local Government Units (LGUs) through their AntiDrug Abuse Councils (ADACs) to facilitate the establishment of community-based treatment and rehabilitation services and interventions to surrenderers found to be of low-risk or having mild substance use disorder. Some LGUs have started to established and operationalize their communitybased treatment and rehabilitation programs based on the provisions provided the (DDB). Other organizations have also offered their support and services for the rehabilitation of drug users and dependents in the communities and one of them is the Simula ng Pag-asa (SIPAG). SIPAG is 12session moral recovery program that is divided into three parts: Family, Recovery, and Accountability., the programFamily focused topics are intended to help restore the family through forgiveness and family relationship-strengthening messages to help them realize that drugs are just a by-product of a dysfunctional family. The recovery session is intended to help the person realize the need for God, that no one can change her/his own except Christ. The last part is focused on Accountability. This part is designed to help the participants see the importance of having a support group outside of the family. Each part is conducted in four sessions. So, the whole whole SIPAG program will last for 12 sessions (Dangerous Drugs Board, 2016) 
In September 2016, the local chief executive gathered representatives from the different sectors and volunteers to map out plans to tackle the influx of drug surrenderees in response to the Oplan "tokhang" of the PNP. The group drew-up a Transformational Rehabilitation Plan that was a CommunityBased Approach to Drug Prevention, Intervention and Moral Recovery Program. The program, a 3Phases modular approach, was implemented with the general objective to enable the participant to understand the process of healing and recovery from their old lifestyles and embrace the new life for the future. Based on the feedback from the surrenderees and their families, the program was effective because it really addressed the inner core of their problems (Mazo, 2017). Also Shafiei (2014) concluded that addiction treatment can be achieved through the cooperation and willingness of the addicts to quit and participation of their families.

\section{METHODS}

The study used descriptive-survey design. Survey questionnaires were distributed among 131 drug surrenderees to gather data. Descriptive statistics were used to analyze the data.

The target population of the study were the 371 participants who successfully completed the 12 session of moral-recovery program. Only 131 of them voluntarily participated in the survey. Data for the kinds of drugs used, type of usage and frequency of use before joining the program and the changes that they experienced after attending the program were collected using selfconstructed questionnaire. The questionnaire was written in tagalog or Pilipino.

Data were tabulated and were analyzed using percentage and frequency table. Impact of the study was determined by comparing the data describing who they are before attending and who they are now after attending the 12 session of moral-recovery program.

\section{RESULTS}

Table 1, summarized the different kinds of drugs used by the drug surrenderees before. Ninetysix percent (96\%) of them use shabu, $2 \%$ marijuana, and $2 \%$ alcohol.

Table 1. Kinds of Drugs Used by the Respondents Before

\begin{tabular}{|c|c|c|c|}
\hline Kinds of Drugs Used & & No. of Respondents & Percentage \\
\hline Shabu & & 126 & $96 \%$ \\
\hline Mairjuan & & 3 & $2 \%$ \\
\hline Alcohol & & 2 & $2 \%$ \\
\hline & Total & 131 & 100 \\
\hline
\end{tabular}


Types of Usage

As indicated in table 2, 79\% of respondents used drugs by sniffing (pagsinghot), $11 \%$ by drinking (pag-inom), $1 \%$ by injection (pagturok) and $9 \%$ in other forms.

Table 2. How the Respondent Used Drugs

\begin{tabular}{|c|c|c|c|}
\hline Types of Usage & & No. of Respondents & Percentage \\
\hline Sniffing (pagsinghot) & & 104 & $79 \%$ \\
\hline Drinking & & 14 & $11 \%$ \\
\hline Injection & & 1 & $1 \%$ \\
\hline Others & & 12 & $9 \%$ \\
\hline & Total & 131 & 100 \\
\hline
\end{tabular}

Frequency of Use

Most (72\%) of the respondents used drugs once a week, $17 \%$ twice a week, and 11\% 3-5 times a week as shown in table 3 .

Table 3. Frequency of Drug Use

\begin{tabular}{|c|c|c|c|}
\hline Frequency & & No. of Respondents & Percentage \\
\hline Once a Week & & 94 & $72 \%$ \\
\hline Twice a Week & & 22 & $17 \%$ \\
\hline $3-5$ times a Week & & 15 & $11 \%$ \\
\hline & Total & 131 & 100 \\
\hline
\end{tabular}

Changes After Attending the Moral-Recovery Program

The summary of changes experienced by the respondents in their lives after attending the 12 sessions moral-recovery program are shown in table 4.

These respondents who were addicted to drugs now $85 \%$ of them resolved to stop using drugs. They do not go to church before, now $51 \%$ of them are church goers. Before, they just kept to themselves their problems. Now, $85 \%$ of them disclosed their problems to others. Most of them before prefer to be alone, now $73 \%$ of them are trying to be sociable. Before, they do not care about God and about their lives. Now, $75 \%$ of them wanted to have a better relationship with God and $23 \%$ have a healthier perspective in life and would like to be more responsible to their families. 
Table 4. Changes in the Lives of the Respondents After Attending the Moral-Recovery Program

\begin{tabular}{lcc}
\hline \multicolumn{1}{c}{ Changes After Attending the Program } & No. of Respondents & Percentage \\
\hline Resolved to Stop Using Drugs & 111 & $85 \%$ \\
Attend to Church Regularly & 67 & $51 \%$ \\
Prefer to Disclose Problems with Others & 111 & $85 \%$ \\
Socialized with Others & 96 & $73 \%$ \\
Wanted to Have a Better Relationship with God & 98 & $75 \%$ \\
Have a Healthier Perspective in Life and Would & 23 & $18 \%$ \\
to be More Responsible to their Families & & \\
\hline
\end{tabular}

\section{DISCUSSION}

The main objective of the study is to evaluate the impact of the moral-recovery program conducted by the different religious groups in cooperation with Dangerous Drugs Board (DDB) of the Philippines, Philippine National Police, Local Governments Units, and Non-Government Agencies and various business sectors. The program can be very useful in the helping the drug surrenderees develop a heathier perspective in life. The program can now be used by the government and non-government agencies, and religious sectors a standard program to other drug surrenderees in other part of the country.

The overall results of the study showed that the respondents were using shabu, the most, once a week by sniffing before attending the 12 session moral-recovery program. After attending the moral-recovery program, there were significant changes in their lives. They learned the disadvantages of using drugs and resolved to stop using them. They learned about God, attend church regularly and wanted to have a better relationship with Him. They learned to socialized and disclosed their problems with others.

\section{Conclusion}

The study concludes that the moral-recovery program had impacted the life of the respondents from being a drug dependent to healthier perspective in life. It is suggested that this program be replicated in other regions of the Philippines or other countries who have the same problem for research.

\section{REFERENCES}

Dangerous Drugs Board. (2016). Community-Based Treatment and Rehabilitation Resources. Retrieved from https://www.ddb.gov.ph/sidebar/301-community-based-treatmentand-rehabilitation-resources. 
United Nations Office on Drugs and Crimes. (2017). Executive Summary: Conclusions and Policy Implications. United Nations Publication, Sales No. E.17.X1.6: 9-11.

United Nations Office on Drugs and Crimes. (2018). Executive Summary: Conclusions and Policy Implications. United Nations Publication, Sales No. E.18.X1.9: 9-10.

Kandel, D.B. (2002). Stages and Pathways of Drug Involvement: Examining the Gateway Hypothesis. Cambridge: Cambridge University Press.

Goldstein RZ, Volkow ND. Dysfunction of the Prefrontal Cortex in Addiction: Neuroimaging Findings and Clinical Implications. Nat Rev Neurosci. 2011;12(11):652-669. doi:10.1038/nrn3119.

Journey Pure. (2019). Differences Between Physical and Psychological Addiction. Retrieved from https://emeraldcoastjourneypure.com/physical-vs-psychological-addiction/.

National Institute on Drug Abuse. (2018). Drugs, Brains, and Behavior: The Science of Addiction. Retrieved from https://www.drugabuse.gov/publications/drugs-brainsbehavior-science-addiction/drug-misuse-addiction\#footnote.

Mazo, G. N. (2017). Transformational, Rehabilitation: Community-Based Intervention to End the Drug Menace. International Journal of Research-Granthaalayah, Vol.5(12):183

Philstar. (2019). PNP, PDEA, NBI Agree: Duterte's Estimate of 8M Drug Users has Basis. Retrieved from https://www.philstar.com/headlines/2019/02/28/1897470/pnp-pdeanbi-agree-dutertes-estimate-8m-drug-users-has-basis.

GMA News Online. (2017). PNP to Launch Community-based Recovery Program for Drug Users. Retrieved from https://www.gmanetwork.com/news/news/nation/627573/pnp-to-launchcommunity-based-recovery-program-for-drug-suspects/story/.

Inquirer. (2019). Locsin: 1.4 Million Filipino Drug Users Surrendered for Rehab in War VS Drugs. Retrieved from https://globalnation.inquirer.net/173624/locsin-1-4-millionfilipino-drug-users-surrendered-for-rehab-in-war-vs-drugs.

Philippine Drug Enforcement Agency. (2012). The Philippine Drug Situation. Retrieved from http://pdea.gov.ph/images/AnnualReport/2012AR/2012PhilippineDrugSituation.pdf

Shaiei, E.; Hoseni, A. F.; Bibak, A; and Azmal, A. (2014). High Risk Situations Predicting Relapse in Self-Referred Addicts to Bushehr Province Substance Abuse Treatment Centers. Retrieved from https://www.ncbi.nlm.nih.gov/pmc/articles/PMC4080483/ 